\title{
Correction to: Unintended consequences of decreased PSA-based prostate cancer screening
}

\author{
Thomas Ahlering ${ }^{1} \cdot$ Linda My Huynh $^{1} \cdot$ Kamaljot S. Kaler $^{1} \cdot$ Stephen Williams ${ }^{2} \cdot$ Kathryn Osann $^{3} \cdot$ Jean Joseph $^{4}$. \\ David Lee $^{5}$. John W. Davis ${ }^{6} \cdot$ Ronney Abaza $^{7}$. Jihad Kaouk ${ }^{8}$. Vipul Patel ${ }^{9} \cdot$ Isaac Yi Kim $^{10}$. James Porter ${ }^{11}$. \\ Jim C. $\mathrm{Hu}^{12}$
}

Published online: 22 July 2019

(c) Springer-Verlag GmbH Germany, part of Springer Nature 2019

\section{Correction to: World Journal of Urology (2019) 37:489-496 https://doi.org/10.1007/s00345-018-2407-3}

In the original publication, part of funding information was missed in the 'Acknowledgement' section. The complete text should read as below.

Acknowledgements Special thanks to the Urology research coordinators, fellows, and students who have contributed to data collection and collation: Erica Huang, Anthony Warner, Omesh Ranasinghe, Bonita Powell, Kellie McWilliams, Mary Achim, Pascal Mouracade (MD), Tadzia Harvey, Brian Shinder (MD). In support of Dr. Edward and Arthur Lui (MD) and in memory of their parents Mr. and Mrs. L.H.M

The original article can be found online at https://doi.org/10.1007/ s00345-018-2407-3.

Thomas Ahlering

tahlerin@uci.edu

1 Department of Urology, University of California, Irvine Health, 333 City Blvd West, Suite 2100, Orange, CA 92868, USA

2 Division of Urology, Department of Surgery, University of Texas Medical Branch at Galveston, Galveston, TX, USA

3 Division of Hematology-Oncology, Department of Medicine, University of California, Irvine, Irvine, CA, USA

4 Department of Urology, University of Rochester, Rochester, NY, USA

5 Perelman School of Medicine, University of Pennsylvania, Philadelphia, PA, USA
Lui. Dr Jim Hu reported receiving funding from The Frederick J. and Theresa Dow Wallace Fund of the New York Community Trust.

Publisher's Note Springer Nature remains neutral with regard to jurisdictional claims in published maps and institutional affiliations.
6 UT MD Anderson Cancer Center, Houston, TX, USA

7 Department of Urology, Ohio Health Robotic Urologic Surgeons, Dublin, OH, USA

8 Department of Urology, Cleveland Clinic, Cleveland, $\mathrm{OH}$, USA

9 Department of Urology, Florida Celebration Health, Kissimmee, FL, USA

10 Department of Urology, Rutgers Cancer Center of New Jersey, New Brunswick, NJ, USA

11 Department of Urology, Swedish Medical Center, Seattle, WA, USA

12 Weill Cornell Medicine, New York, NY, USA 